\title{
Assessment of CFD Capability for Hypersonic Shock Wave Laminar Boundary Layer Interactions
}

\author{
Mehrnaz Rouhi Youssefi * and Doyle Knight \\ Department of Mechanical and Aerospace Engineering, Rutgers-The State University of New Jersey, \\ New Brunswick, NJ 08903, USA; doyleknight@gmx.com \\ * Correspondence: mehrnaz.ry@rutgers.edu; Tel.: +1-860-617-8745 \\ Academic Editors: Hossein Zare-Behtash and Kiran Ramesh \\ Received: 23 December 2016; Accepted: 18 April 2017; Published: 25 April 2017
}

\begin{abstract}
The goal of this study is to assess CFD capability for the prediction of shock wave laminar boundary layer interactions at hypersonic velocities. More specifically, the flow field over a double-cone configuration is simulated using both perfect gas and non-equilibrium Navier-Stokes models. Computations are compared with recent experimental data obtained from measurements conducted in the LENS XX (Large Energy National Shock Expansion Tunnel Version 2) at the Calspan University of Buffalo Research Center (CUBRC). Four separate cases of freestream conditions are simulated to examine the models for a range of stagnation enthalpies from $5.44 \mathrm{MJ} / \mathrm{kg}$ to $21.77 \mathrm{MJ} / \mathrm{kg}$ and Mach numbers from 10.9 to 12.82 .
\end{abstract}

Keywords: CFD; hypersonic; shock wave; laminar; real gas; non-equilibrium

\section{Introduction}

The performance of hypersonic air vehicles can be adversely affected by the interaction of shock waves and boundary layers. Some of the issues associated with this interaction at hypersonic flight are drag rise, high localized aerothermal loads, formation of recirculation zones and pressure fluctuations. Hence, accurate prediction of the flow field is important to overcome these problems [1].

During the past twenty years, numerous studies have assessed the capability of Computational Fluid Dynamics (CFD) to predict hypersonic shock wave laminar boundary layer interactions [2-9]. These efforts have focused on simple axisymmetric geometries that were chosen to elucidate the important flow field physics in a nominally two-dimensional environment without the three-dimensional effects associated with a finite model spanwise dimension. These geometries include the hollow cylinder flare [10] and double-cone [11,12]. In 2001, a "blind" study of CFD capability for the prediction of the hollow cylinder flare and double-cone configurations was conducted $[13,14]$. Perfect gas and non-equilibrium Navier-Stokes and Direct Simulation Monte Carlo (DSMC) computations were solicited from a group of CFD experts for comparison with experiments performed in the shock tunnels at the Calspan University of Buffalo Research Center (CUBRC) at Mach numbers from 9.5 to 11.3. CFD simulations were compared with experimental data for surface heat transfer and pressure. In general, good agreement between the continuum non-equilibrium Navier-Stokes simulations and experiment was observed except for a consistent overprediction of heat transfer on the forward cone surface upstream of the shock wave laminar boundary layer interaction and also in the vicinity of the reattachment for some cases [14]. However, a complete assessment of CFD capability for the prediction of these experiments was complicated by the lack of complete information regarding the test section inflow conditions due to vibrational relaxation of the flow (i.e., non-equilibrium flow field effects) in the shock tunnel nozzle [15]. A number of computational studies were subsequently conducted to account for the nonequilibrium structure of the test section inflow and provide proper 
inflow conditions for the simulations $[16,17]$. Nonetheless, uncertainties regarding the test section inflow properties remained.

In 2014, MacLean et al. [18-20] published a new set of experiments from CUBRC on hypersonic shock wave laminar boundary layer interactions for the double-cone and hollow cylinder flare configurations. In contrast to the earlier experiments described above that constituted the test matrix for the 2001 "blind" study, these experiments were performed in the LENS XX expansion tunnel. This facility generates equilibrium flow conditions in the test section, thus reducing any uncertainty regarding the inflow conditions for CFD simulations. This new experimental test matrix examined freestream stagnation enthalpies from $5.4 \mathrm{MJ} / \mathrm{kg}$ to $21.8 \mathrm{MJ} / \mathrm{kg}$, Mach numbers from 10.9 to 13.2 and Reynolds numbers per meter from $1.1 \times 10^{5}$ to $4.2 \times 10^{5}$. The Reynolds numbers based on the model lengths of $194 \mathrm{~mm}$ to $220 \mathrm{~mm}$ were sufficiently low to ensure laminar conditions throughout the flow field. This new experimental dataset thus offers a unique opportunity to examine CFD capability for the prediction of hypersonic shock wave laminar boundary layer interaction with fully-characterized equilibrium inflow conditions.

The objective of this paper is to assess CFD capability for prediction of hypersonic shock wave laminar boundary layer interactions based on comparison with the new experimental dataset from MacLean et al. The configuration chosen is the double-cone. Given the opportunity to compare computations with the new experimental dataset for the first time, our approach is inspired by Occam's razor: select the (continuum) model(s) with the fewest assumptions. The simplest equilibrium model is the perfect gas laminar Navier-Stokes equations. This model assumes both thermodynamic and thermochemical equilibrium. The simplest nonequilibrium model is the perfect gas laminar Navier-Stokes equations incorporating thermodynamic non-equilibrium (i.e., vibrational-translational/rotational energy exchange) and thermochemical non-equilibrium. We have chosen the classical Landau-Teller model [21] for vibrational-translational/rotational energy exchange and the Park I [22] thermochemistry model. The Park I model is the simplest finite-rate air thermochemistry model, which includes just five species and the minimum number of reactions among other air thermochemistry models.

\section{Experiment}

The experiments were performed in the LENS XX expansion tunnel at the Calspan University of Buffalo Research Center (CUBRC) and are described in MacLean et al. [19,20]. A photograph and a schematic diagram of the double-cone configuration are shown in Figure 1. Pressure and heat transfer instrumentation were incorporated in the model to accurately record the flow field development over the double-cone configuration with semi-angles of $25^{\circ}$ and $55^{\circ}$. The red points in Figure 1a are the pressure transducers. The freestream conditions are listed in Table 1. The inflow is equilibrium dry air with mass fractions of $\mathrm{N}_{2}$ and $\mathrm{O}_{2}$ equal to 0.765 and 0.235 , respectively. The uncertainties in the freestream conditions are estimated to be $\pm 3 \%$ for velocity, $\pm 3 \%$ for temperature and $\pm 7 \%$ for density [23]. The model surface is isothermal at $T_{w}=300 \mathrm{~K}$. The uncertainty in the experimental measurements is $\pm 10 \%$ [23].

Table 1. Freestream conditions for double-cone experiments.

\begin{tabular}{cccccccc}
\hline Run No. & $\begin{array}{c}\text { Stagnation } \\
\text { Enthalpy } \\
(\mathbf{M J} / \mathbf{k g})\end{array}$ & $\begin{array}{c}\text { Mach } \\
\text { Number }\end{array}$ & $\begin{array}{c}\text { Pitot } \\
\text { Pressure } \\
\mathbf{( k P a )}\end{array}$ & $\begin{array}{c}\text { Unit Reynolds } \\
\mathbf{N u m b e r} \\
\mathbf{1 1 0}^{\mathbf{6}} \mathbf{~ m}^{-\mathbf{1}}\end{array}$ & $\begin{array}{c}\text { Velocity } \\
\mathbf{( \mathbf { k m } / \mathbf { s } )}\end{array}$ & $\begin{array}{c}\text { Density } \\
\mathbf{( g / \mathbf { m } ^ { 3 } )}\end{array}$ & $\begin{array}{c}\text { Static } \\
\text { Temperature } \\
\mathbf{( K )}\end{array}$ \\
\hline 1 & 5.44 & 12.2 & 5.1 & 0.14 & 3.246 & 0.499 & 175 \\
2 & 9.65 & 10.90 & 17.5 & 0.19 & 4.303 & 0.984 & 389 \\
4 & 21.77 & 12.82 & 39.5 & 0.20 & 6.497 & 0.964 & 652 \\
6 & 15.23 & 11.46 & 59.0 & 0.39 & 5.466 & 2.045 & 573 \\
\hline
\end{tabular}




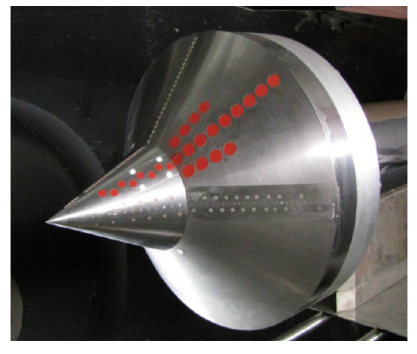

(a)

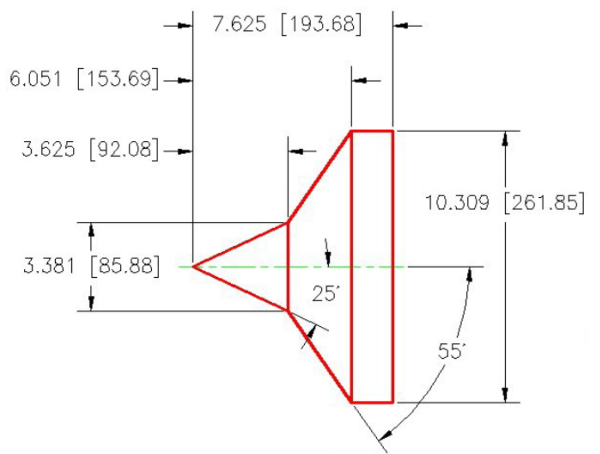

(b)

Figure 1. Double-cone configuration. (a) Double-cone model installed in the LENS XX tunnel;

(b) Dimensions in inches ( $\mathrm{mm}$ ).

\section{Details of Computations}

Simulations for the double-cone were performed using two different models, namely perfect gas laminar Navier-Stokes (denoted "perfect gas Navier-Stokes model") and non-equilibrium laminar Navier-Stokes incorporating the Park I thermochemistry model [22] and Landau-Teller vibrational-translational energy exchange [21] (denoted "non-equilibrium Navier-Stokes model").

\subsection{Perfect Gas Laminar Navier-Stokes}

The governing equations are the laminar Navier-Stokes equations for a perfect gas. Using the Einstein summation notation,

$$
\begin{aligned}
\frac{\partial \rho}{\partial t}+\frac{\partial \rho u_{j}}{\partial x_{j}} & =0 \\
\frac{\partial \rho u_{i}}{\partial t}+\frac{\partial \rho u_{i} u_{j}}{\partial x_{j}} & =-\frac{\partial p}{\partial x_{i}}+\frac{\partial \tau_{i j}}{\partial x_{j}} \\
\frac{\partial \rho \varepsilon}{\partial t}+\frac{\partial}{\partial x_{j}}(\rho \varepsilon+p) u_{j} & =-\frac{\partial q_{j}}{\partial x_{j}}+\frac{\partial \tau_{i j} u_{i}}{\partial x_{j}} \\
p & =\rho R T
\end{aligned}
$$

where the total energy per unit mass $\varepsilon$ is:

$$
\varepsilon=e+\frac{1}{2} u_{j} u_{j}
$$

where the internal energy per unit mass $e$ is:

$$
e=c_{v} T
$$

and the heat flux vector and laminar viscous stress tensor are:

$$
\begin{aligned}
q_{j} & =-k \frac{\partial T}{\partial x_{j}} \\
\tau_{i j} & =-\frac{2}{3} \mu \frac{\partial u_{k}}{\partial x_{k}} \delta_{i j}+\mu\left(\frac{\partial u_{i}}{\partial x_{j}}+\frac{\partial u_{j}}{\partial x_{i}}\right)
\end{aligned}
$$

The molecular viscosity $\mu$ is defined by Sutherland's Law and the molecular Prandtl number $\operatorname{Pr}=\mu c_{p} / k$ is 0.72 . The gas constant $R=287 \mathrm{~J} / \mathrm{kg} \cdot \mathrm{K}$ for air. 


\subsection{Non-Equilibrium Laminar Navier-Stokes}

We consider a reacting mixture of gases with density $\rho_{\alpha}$ for $\alpha=1, \ldots, n$ of which $\alpha=1, \ldots, m$ constitute diatomic (or polyatomic) species and the remainder $(i=m+1, \ldots, n)$ represent monatomic species.

The governing equations for nonequilibrium laminar Navier-Stokes flow consists of conservation of mass, momentum, total energy, vibrational energy and equation of state:

$$
\begin{array}{r}
\frac{\partial \rho_{\alpha}}{\partial t}+\frac{\partial \rho_{\alpha} u_{j}}{\partial x_{j}}=\dot{\omega}_{\alpha}^{\text {spe }}+\frac{\partial}{\partial x_{j}}\left[\rho D \frac{\partial Y_{\alpha}}{\partial x_{j}}\right] \quad \text { for } \alpha=1, \ldots, n \\
\frac{\partial \rho u_{i}}{\partial t}+\frac{\partial \rho u_{i} u_{j}}{\partial x_{j}}=-\frac{\partial p}{\partial x_{i}}+\frac{\partial \tau_{i j}}{\partial x_{j}} \quad \text { for } i=1,2,3 \\
\frac{\partial \rho \varepsilon}{\partial t}+\frac{\partial}{\partial x_{j}}(\rho \varepsilon+p) u_{j}=\frac{\partial \tau_{i j} u_{i}}{\partial x_{j}}-\frac{\partial q_{j}}{\partial x_{j}} \\
\frac{\partial \rho e_{\alpha}^{\text {vib }}}{\partial t}+\frac{\partial \rho e_{\alpha}^{\text {vib }} u_{j}}{\partial x_{j}}=-\frac{\partial q_{\alpha_{j}}^{\text {vib }}}{\partial x_{j}}+\dot{\omega}_{\alpha}^{\text {vib }} \quad \text { for } \alpha=1, \ldots, m \\
p=T \sum_{\alpha=1}^{n} \rho_{\alpha} R_{\alpha}
\end{array}
$$

In Equation (9), $\rho_{\alpha}$ is the density of species $\alpha$; the mass-averaged velocity is $u_{j}$; and $\rho$ is the mixture density:

$$
\rho=\sum_{\alpha=1}^{N} \rho_{\alpha}
$$

The mass fraction is defined as:

$$
Y_{\alpha}=\frac{\rho_{\alpha}}{\rho}
$$

The rate of production of species $\alpha$ is denoted as $\dot{\omega}_{\alpha}^{\text {spe }}$ and defined as:

$$
\dot{\omega}_{\alpha}^{\text {spe }}=\mathcal{M}_{\alpha} \sum_{j=1}^{J}\left(v_{\alpha, j}^{\prime \prime}-v_{\alpha, j}^{\prime}\right) k_{f, j}\left[\prod_{l=1}^{n}\left(\frac{\rho_{l}}{\mathcal{M}_{l}}\right)^{v_{l, j}^{\prime}}-\frac{1}{k_{e, j}} \prod_{l=1}^{n}\left(\frac{\rho_{l}}{\mathcal{M}_{l}}\right)^{v_{l, j}^{\prime \prime}}\right] \quad \text { for } \alpha=1, \ldots, n
$$

for the general reaction expressions:

$$
v_{1, j}^{\prime} X_{1}+\ldots+v_{n, j}^{\prime} X_{n} \rightleftharpoons v_{1, j}^{\prime \prime} X_{1}+\ldots+v_{n, j}^{\prime \prime} X_{n} \quad \text { for } j=1, \ldots, J
$$

where $J$ is the number of reactions and $v_{\alpha, j}^{\prime}$ and $v_{\alpha, j}^{\prime \prime}$ are the stoichiometric coefficients of the reactants and products of species $X_{\alpha}$ in the $j^{\text {th }}$ reaction.

The diffusion of species is modeled by Fick's law assuming a uniform diffusivity $D$ defined by:

$$
D=\frac{\mu}{\rho S c}
$$

where $S c=0.7$ is the constant Schmidt number and $\mu$ is the molecular viscosity defined by Sutherland's Law.

In Equation (10), $\tau_{i j}$ is the laminar viscous stress tensor defined by Equation (8).

The total energy per unit mass $\varepsilon$ is defined in the same way as in Equation (5), but here, the internal energy per unit mass $e$ is the sum of the internal energies of each of the $n$ species:

$$
e=\sum_{\alpha=1}^{n} \frac{\rho_{\alpha}}{\rho} e_{\alpha}
$$


where the internal energy per unit mass of each species $e_{\alpha}$ is the sum of an equilibrium internal energy $e_{\alpha}^{\text {eq }}(T)$ due to random translational energy and rotational energy (in the case of molecules) at a bulk equilibrium temperature $T$ and a non-equilibrium internal energy $e_{\alpha}^{\text {vib }}\left(T_{\alpha}^{\text {vib }}\right)$ due to vibrational excitation (in the case of molecules):

$$
e_{\alpha}=e_{\alpha}^{\mathrm{eq}}(T)+e_{\alpha}^{\mathrm{vib}}\left(T_{\alpha}^{\mathrm{vib}}\right)
$$

The equilibrium internal energy of species $\alpha$ is:

$$
e_{\alpha}^{\mathrm{eq}}(T)=h_{f_{\alpha}}^{o}+\int_{T_{\mathrm{eq}}}^{T} c_{v_{\alpha}}(T) d T
$$

In Equation (11), the heat transfer vector is defined by:

$$
q_{j}=-k \frac{\partial T}{\partial x_{j}}-\sum_{\alpha=1}^{m} k_{\alpha}^{\mathrm{vib}} \frac{\partial T_{\alpha}^{\mathrm{vib}}}{\partial x_{j}}-\sum_{\alpha=1}^{n} \rho h_{\alpha} D_{\alpha} \frac{\partial Y_{\alpha}}{\partial x_{j}}
$$

The static enthalpy per unit mass for species $\alpha$ is:

$$
h_{\alpha}=h_{f_{\alpha}}^{o}+\int_{T_{\mathrm{ref}}}^{T} c_{p_{\alpha}}(T) d T
$$

where $h_{f_{\alpha}}^{o}$ is the enthalpy of formation of species $\alpha$ at $T_{\text {ref }}$.

In Equation (12) the heat transfer vector is:

$$
q_{\alpha_{j}}^{\mathrm{vib}}=-k_{\alpha}^{\mathrm{vib}} \frac{\partial T_{\alpha}^{\mathrm{vib}}}{\partial x_{j}}-\rho D_{\alpha} e_{\alpha}^{\mathrm{vib}} \frac{\partial Y_{\alpha}}{\partial x_{j}}
$$

The source term is:

$$
\dot{\omega}_{\alpha}^{\mathrm{vib}}=\rho_{\alpha} \dot{e}_{\alpha}^{\mathrm{vib}}+\dot{\omega}_{\alpha}^{\text {spe }} e_{\alpha}^{\mathrm{vib}}
$$

where $\dot{e}_{\alpha}^{\text {vib }}$ is the translational-vibrational energy transfer per unit mass of species $\alpha$ defined by the Landau-Teller model [24]

$$
\dot{e}_{\alpha}^{\mathrm{vib}}=\frac{e_{\alpha}^{\mathrm{vib}}(T)-e_{\alpha}^{\mathrm{vib}}\left(T_{\alpha}^{\mathrm{vib}}\right)}{\tau_{\alpha}}
$$

where $e_{\alpha}^{\text {viv }}$ is the equilibrium vibrational energy per unit mass of species $\alpha$ defined by:

$$
e_{\alpha}^{\mathrm{vib}}{ }^{*}(T)=\sum_{n=1}^{N_{\Theta, \alpha}} \frac{R_{\alpha} \Theta_{\alpha}^{\mathrm{vib}(n)}}{\exp \left(\Theta_{\alpha}^{\mathrm{vib}(n)} / T\right)-1}
$$

and $N_{\Theta, \alpha}$ is the number of characteristic temperatures $\Theta_{\alpha}^{\mathrm{vib}(n)}$ and $\tau_{\alpha}$ is the relaxation time [25] of species $\alpha$ defined by:

$$
\tau_{\alpha}=\frac{\sum_{\beta=1}^{n} M_{\beta}}{\sum_{\beta=1}^{n} M_{\beta} \tau_{\alpha \beta}^{-1}}
$$

where $M_{\alpha}=\rho_{\alpha} / \mathcal{M}_{\alpha}$ is the molar concentration of species $\alpha$ and $\tau_{\alpha \beta}$ is the characteristic relaxation time of species $\alpha$ resulting from collisions with species $\beta$ defined by [25]:

$$
\tau_{\alpha \beta}=\frac{1}{p} \exp \left[A_{\alpha \beta}\left(T^{-\frac{1}{3}}-B_{\alpha \beta}\right)-18.42\right] \quad \text { atm-s }
$$

where:

$$
A_{\alpha \beta}=0.00116 \mathcal{M}_{\alpha \beta}^{\frac{1}{2}} \Theta_{v_{\alpha}}^{\frac{4}{3}} \text { and } \quad B_{\alpha \beta}=0.015 \mathcal{M}_{\alpha \beta}^{\frac{1}{4}}
$$


and the averaged molecular weight is defined by:

$$
\mathcal{M}_{\alpha \beta}=\frac{\mathcal{M}_{\alpha} \mathcal{M}_{\beta}}{\mathcal{M}_{\alpha}+\mathcal{M}_{\beta}}
$$

In Equation (13), the gas constant $R_{\alpha}$ for species $\alpha$ is:

$$
R_{\alpha}=\frac{\mathcal{R}}{\mathcal{M}_{\alpha}}
$$

where $\mathcal{R}$ is the universal gas constant and $\mathcal{M}_{\alpha}$ is the molecular weight of species $\alpha$.

The non-equilibrium Navier-Stokes simulations used the thermochemistry model proposed by Park [22] comprising five species $\left(\mathrm{N}_{2}, \mathrm{O}_{2}, \mathrm{NO}, \mathrm{N}, \mathrm{O}\right)$ and seventeen reactions (Table 2).

The double-cone boundary type is no-slip with isothermal surface at $300 \mathrm{~K}$. Additionally, the surface may be considered non-catalytic (i.e., $\frac{\partial Y_{i}}{\partial n}=0$ ) or a fully-catalytic (i.e., equilibrium composition at $T_{w}$ ). Inflow and upper boundaries are fixed at freestream conditions, while the outflow has been set to a zero gradient boundary condition. The extent of the simulation domain and boundary conditions is shown in Figure 2.

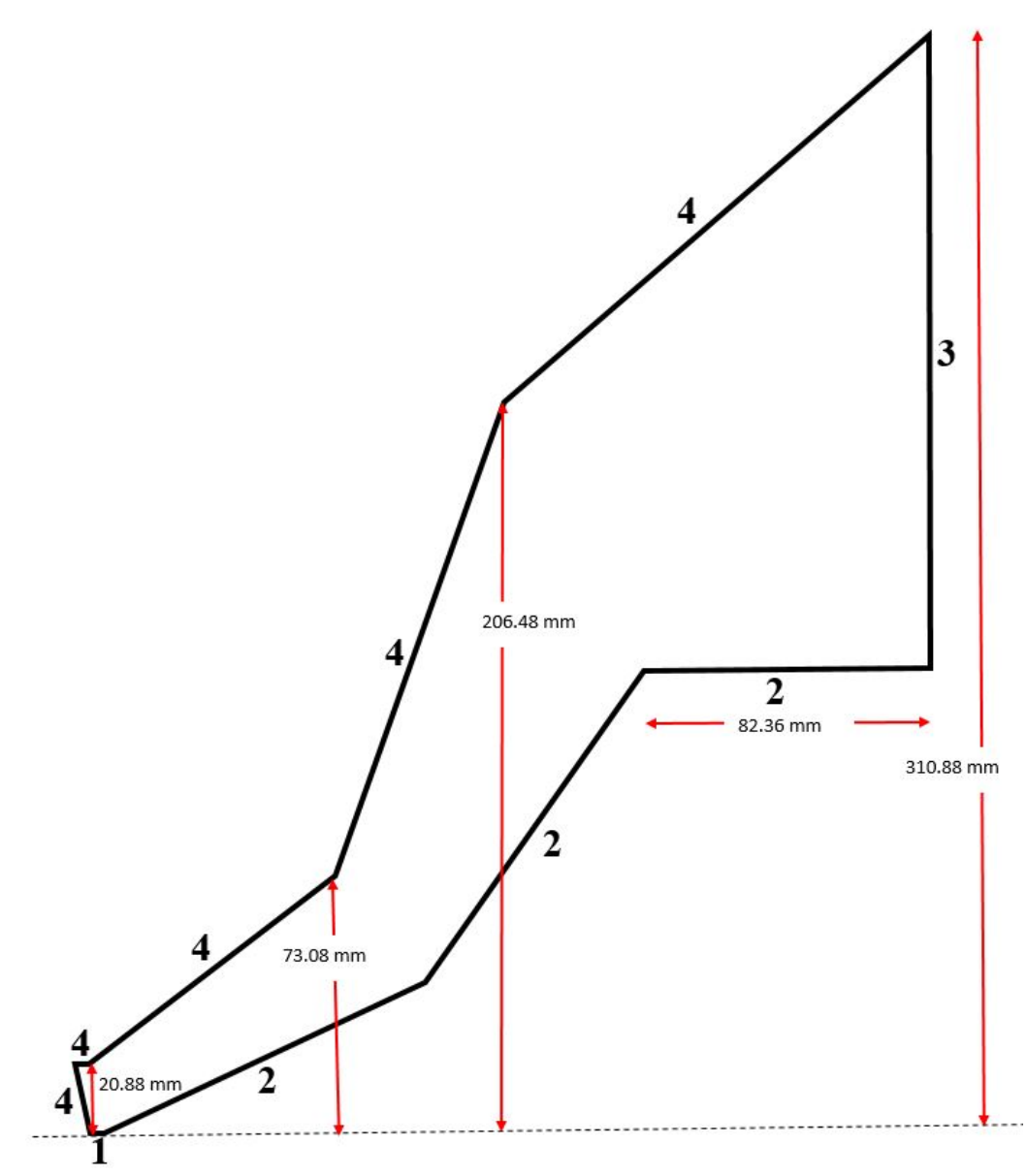

Figure 2. Extent of the domain and boundary conditions. 1: Axis of symmetry; 2: no slip, constant wall temperature; 3: zero gradient; 4: freestream specified. 
Table 2. Thermochemistry model reactions.

\begin{tabular}{|c|c|c|c|c|c|c|c|c|c|c|}
\hline Reaction & $\begin{array}{c}C \\
\left(m^{3} / \mathrm{kg} \cdot \text { mole } \cdot \mathrm{s}\right)\end{array}$ & $\eta$ & $\begin{array}{l}\epsilon / k \\
(\mathrm{~K})\end{array}$ & $\alpha$ & $\beta$ & $A_{1}$ & $A_{2}$ & $A_{3}$ & $A_{4}$ & $A_{5}$ \\
\hline$N_{2}+N_{2} \rightarrow N+N+N_{2}$ & $3.70 \times 10^{18}$ & -1.6 & 113,200 & 0.5 & 0.5 & 10.81 & -12.61 & 0.683 & -0.118 & 0.006 \\
\hline$N_{2}+N \rightarrow N+N+N$ & $1.11 \times 10^{19}$ & -1.6 & 113,200 & 0.5 & 0.5 & 10.81 & -12.61 & 0.683 & -0.118 & 0.006 \\
\hline $\mathrm{N}_{2}+\mathrm{NO} \rightarrow \mathrm{N}+\mathrm{N}+\mathrm{NO}$ & $3.70 \times 10^{18}$ & -1.6 & 113,200 & 0.5 & 0.5 & 10.81 & -12.61 & 0.683 & -0.118 & 0.006 \\
\hline $\mathrm{N}_{2}+\mathrm{O}_{2} \rightarrow \mathrm{N}+\mathrm{N}+\mathrm{O}_{2}$ & $3.70 \times 10^{18}$ & -1.6 & 113,200 & 0.5 & 0.5 & 10.81 & -12.61 & 0.683 & -0.118 & 0.006 \\
\hline $\mathrm{N}_{2}+\mathrm{O} \rightarrow \mathrm{N}+\mathrm{N}+\mathrm{O}$ & $1.11 \times 10^{19}$ & -1.6 & 113,200 & 0.5 & 0.5 & 10.81 & -12.61 & 0.683 & -0.118 & 0.006 \\
\hline $\mathrm{N}_{2}+\mathrm{O} \rightarrow \mathrm{NO}+\mathrm{N}$ & $3.18 \times 10^{10}$ & 0.1 & 37,700 & 1.0 & 0.0 & 2.349 & -4.828 & 0.455 & -0.075 & 0.004 \\
\hline $\mathrm{O}_{2}+\mathrm{N}_{2} \rightarrow \mathrm{O}+\mathrm{O}+\mathrm{N}_{2}$ & $2.75 \times 10^{16}$ & -1.0 & 59,500 & 0.5 & 0.5 & 8.243 & -4.127 & -0.616 & 0.093 & -0.005 \\
\hline $\mathrm{O}_{2}+\mathrm{N} \rightarrow \mathrm{O}+\mathrm{O}+\mathrm{N}$ & $8.25 \times 10^{16}$ & -1.0 & 59,500 & 0.5 & 0.5 & 8.243 & -4.127 & -0.616 & 0.093 & -0.005 \\
\hline $\mathrm{O}_{2}+\mathrm{NO} \rightarrow \mathrm{O}+\mathrm{O}+\mathrm{NO}$ & $2.75 \times 10^{16}$ & -1.0 & 59,500 & 0.5 & 0.5 & 8.243 & -4.127 & -0.616 & 0.093 & -0.005 \\
\hline $\mathrm{O}_{2}+\mathrm{O}_{2} \rightarrow \mathrm{O}+\mathrm{O}+\mathrm{O}_{2}$ & $2.75 \times 10^{16}$ & -1.0 & 59,500 & 0.5 & 0.5 & 8.243 & -4.127 & -0.616 & 0.093 & -0.005 \\
\hline $\mathrm{O}_{2}+\mathrm{O} \rightarrow \mathrm{O}+\mathrm{O}+\mathrm{O}$ & $8.25 \times 10^{16}$ & -1.0 & 59,500 & 0.5 & 0.5 & 8.243 & -4.127 & -0.616 & 0.093 & -0.005 \\
\hline $\mathrm{NO}+\mathrm{O} \rightarrow \mathrm{N}+\mathrm{O}_{2}$ & $2.16 \times 10^{5}$ & 1.29 & 19,220 & 1.0 & 0.0 & 0.215 & -3.657 & 0.843 & -0.136 & 0.007 \\
\hline $\mathrm{NO}+\mathrm{N}_{2} \rightarrow \mathrm{N}+\mathrm{O}+\mathrm{N}_{2}$ & $2.30 \times 10^{14}$ & -0.5 & 75,500 & 0.5 & 0.5 & 8.457 & -7.784 & 0.228 & -0.043 & 0.002 \\
\hline $\mathrm{NO}+\mathrm{NO} \rightarrow \mathrm{N}+\mathrm{O}+\mathrm{NO}$ & $2.30 \times 10^{14}$ & -0.5 & 75,500 & 0.5 & 0.5 & 8.457 & -7.784 & 0.228 & -0.043 & 0.002 \\
\hline $\mathrm{NO}+\mathrm{O}_{2} \rightarrow \mathrm{N}+\mathrm{O}+\mathrm{O}_{2}$ & $2.30 \times 10^{14}$ & -0.5 & 75,500 & 0.5 & 0.5 & 8.457 & -7.784 & 0.228 & -0.043 & 0.002 \\
\hline $\mathrm{NO}+\mathrm{N} \rightarrow \mathrm{N}+\mathrm{O}+\mathrm{N}$ & $4.60 \times 10^{14}$ & -0.5 & 75,500 & 0.5 & 0.5 & 8.457 & -7.784 & 0.228 & -0.043 & 0.002 \\
\hline $\mathrm{NO}+\mathrm{O} \rightarrow \mathrm{N}+\mathrm{O}+\mathrm{O}$ & $4.60 \times 10^{14}$ & -0.5 & 75,500 & 0.5 & 0.5 & 8.457 & -7.784 & 0.228 & -0.043 & 0.002 \\
\hline
\end{tabular}

\subsection{Grid Generation}

Two structured multi-block grids were generated using MATLAB. The grid that was used for Run 1 of Table 1 consisted of 4,530,330 cells, and the grid used for Runs 2, 4 and 6 of Table 1 consisted of 1,332,320 cells. A very fine mesh was incorporated near the surface of the double-cone in order to capture the details of the shock boundary layer interaction. Grid sequencing information is shown in Table 3.

Table 3. Grid sequences.

\begin{tabular}{ccccc}
\hline Run Number & Sequence & Grid & Total Number of Cells & Total Number of Cells \\
\hline 1 & & & Real Gas & Perfect Gas \\
1 & 1 & Coarse & 291,600 & 291,600 \\
1 & 2 & Medium & $1,233,630$ & $1,233,630$ \\
\hline 2 & 3 & Fine & & $4,530,330$ \\
2 & 1 & Coarse & 333,080 & \\
\hline 4 & 2 & Medium & $1,332,320$ & \\
4 & 1 & Coarse & 333,080 & \\
\hline 6 & 2 & Medium & $1,332,320$ & \\
6 & 1 & Coarse & 333,080 & \\
\hline
\end{tabular}

\subsection{Solution Algorithm}

The commercial flow solvers GASPex and GASP (General Aerodynamic Simulation Program) [26], respectively, were used by the first author for the perfect gas simulations and the second author for the non-equilibrium simulations. The Reynolds number based on the model length is sufficiently small for all runs (Table 1) that the flow field can be considered fully laminar. There would be a sudden increase in the measured heat transfer if the boundary layer on the forward cone were transitional; however, there is no such increase seen on the forward cone, and therefore, the boundary layer entering the shock wave boundary layer interaction at the forward cone/rear cone intersection is laminar. Furthermore, the experimental heat transfer and pressure data on the entire forward and rear 
cone surface were steady through the test time, which further confirms that the transition to turbulence does not occur $[19,20]$.

Perfect gas simulations for Run 1 were performed using Van Leer's flux-vector splitting [27] and second order upwind reconstruction with the Min-Mod (Minimum Modulus) limiter [28]. The non-equilibrium simulation for Run 1 was performed using Van Leer's flux-vector splitting and second order upwind reconstruction with the Min-Mod limiter. Time integration was performed using implicit dual time stepping [29]. The non-equilibrium simulations for Runs 2 and 6 were performed using the HLLE+ (Harten, Lax, Van Leer and Einfeldt) flux algorithm [30], third order upwind biased reconstruction, the Min-Mod limiter, finite-rate thermochemistry, non-equilibrium vibration for three species $\left(\mathrm{N}_{2}, \mathrm{O}_{2}, \mathrm{NO}\right)$ and the Svehla-Gordon-McBride model for transport properties (viscosity, thermal conductivity). The non-equilibrium simulations for Run 4 were performed using Roe [31] with Harten modification, second order upwind reconstruction, the Min-Mod limiter and iteration to steady state. All of the solution algorithms used in this study are of second order accuracy or higher. According to Druguet [32], the simulation results obtained using any of the nominally second or higher order accurate methods are essentially the same provided that grid convergence of the solution is achieved.

\section{Results and Discussion}

The computed and experimental surface pressure and heat transfer for Run 1 (Table 1) are presented in Figure 3a,b. The $x$-axis is the horizontal distance measured from the tip of the forward cone. The perfect gas Navier-Stokes simulations agree closely with the experimental data except for an underprediction of heat transfer on the forward cone upstream of the shock boundary layer interaction. The non-equilibrium Navier-Stokes simulation generally coincides with the perfect gas Navier-Stokes simulation except for underprediction of the size of the separation region. Specifically, the non-equilibrium Navier-Stokes simulation underpredicts the separation point (as defined by the drop in the surface heat flux) by $0.65 \mathrm{~cm}$. Both simulations accurately predict the pressure plateau associated with the separation region within the experimental uncertainty. The overall level and trend of the computed surface pressure and heat flux in the vicinity of reattachment at $x \approx 10.8 \mathrm{~cm}$ are in agreement with the experiment. Note that an overprediction of peak surface pressure and heat transfer is not necessarily an indication of inaccuracy due to the limited number and spacing of the surface gauges.

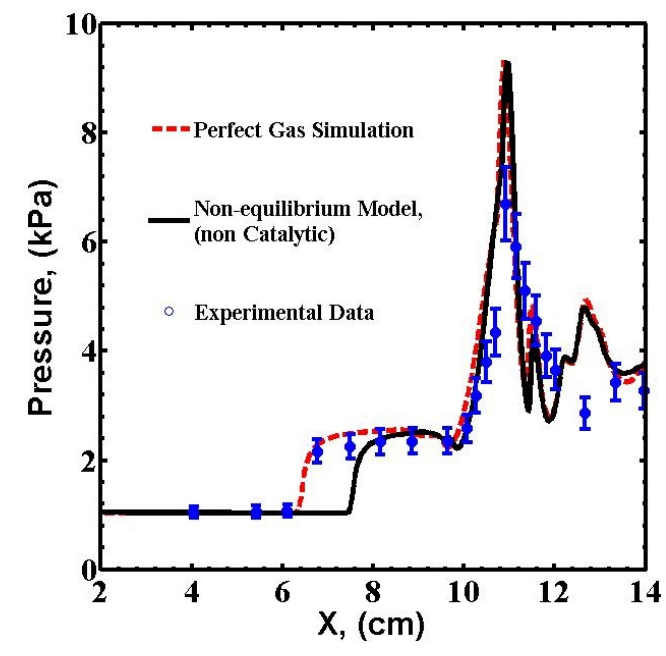

(a)

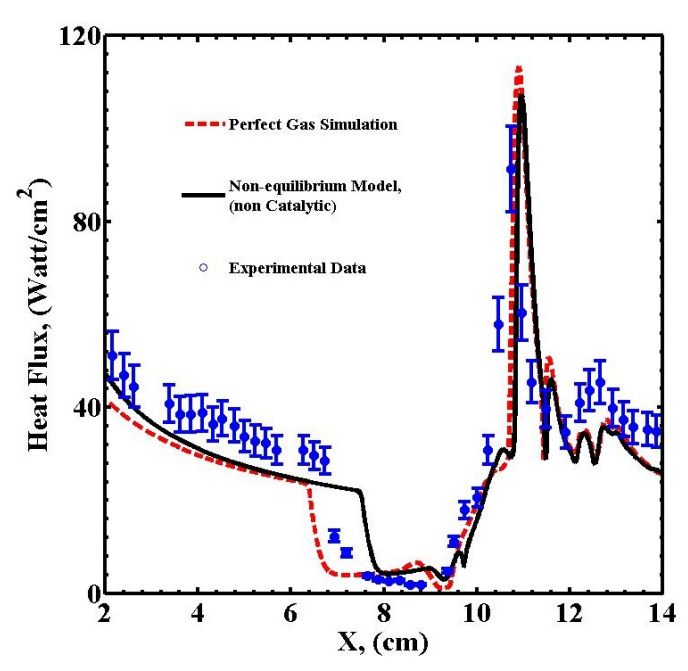

(b)

Figure 3. Computational results for Run 1, Table 1, using perfect gas and non-equilibrium Navier-Stokes models. (a) Surface pressure; (b) Heat transfer rate. 
The flow field structure for Run 1 is illustrated in Figure 4 based on the perfect gas Navier-Stokes simulation. The structure is similar to previous observations $[33,34]$. Figure 4 a shows the entire flow field. The adverse pressure gradient at the cone-cone juncture causes the boundary layer to separate. A weak shock-shock interaction is formed by the separation shock and the oblique shock generated by the first cone. The separation shock strongly interacts with the detached shock generated by the second cone forming a triple point with a transmitted shock directed towards the aft cone. The reattachment shock interacts with the transmitted shock to form a second triple point. A supersonic jet is formed along the surface of the second cone downstream of the impingement point, and it undergoes a series of compressions and expansions as can be seen in Figure $4 \mathrm{~b}$. The flow behind the strong bow shock is subsonic, and therefore, the shape of the jet influences the shock structure.

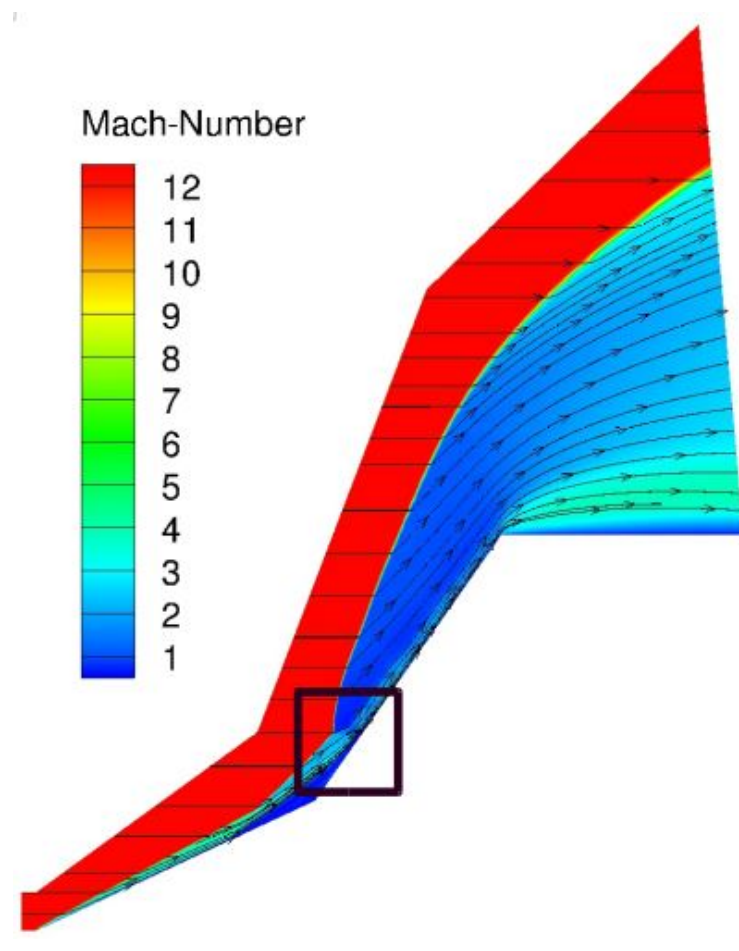

(a)

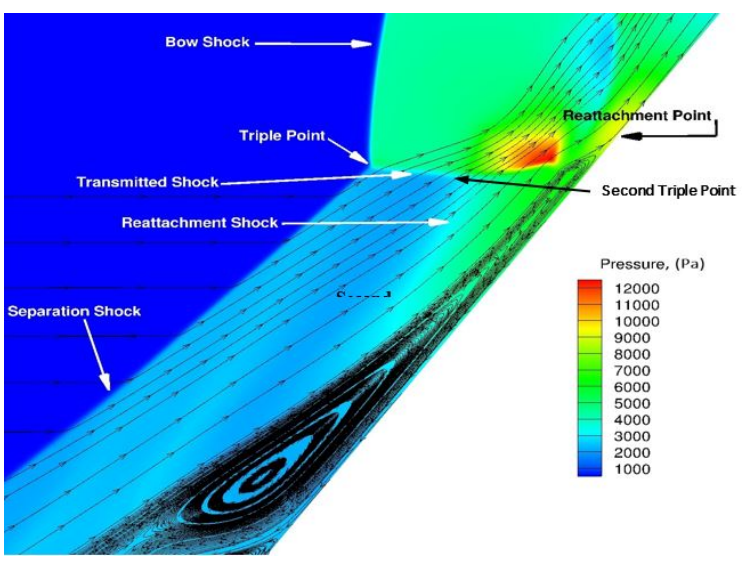

(b)

Figure 4. Flow field structure for Run 1, Table 1, using the perfect gas model. (a) Overall flow field; (b) Enlargement of flow field.

Additional perfect gas simulations were performed for Run 1, Table 1, using different grid sequences from Table 3. As can be seen from Figure 5, the average difference in the computed surface pressure and heat transfer between the two grid levels is less than $5 \%$, i.e., less than half the experimental uncertainty [23]. The non-equilibrium simulations used from $1.2 \mathrm{M}$ cells to $1.3 \mathrm{M}$ cells with similar grid resolution as the perfect gas simulation, in particular in the viscous layers near the walls and in the separation region. The high resolution of the non-equilibrium simulations is evident in Figure 6, which displays the static temperature vs $y-y_{w}$ for Run $4(21.77 \mathrm{MJ} / \mathrm{kg})$ at the location of the peak heat transfer $(x=9.756 \mathrm{~cm})$. The ordinate $y-y_{w}$ is the $y$-distance above the wall at $x=9.756 \mathrm{~cm}$ measured along a constant grid line, which is at an angle of $72.86^{\circ}$ with respect to the rear cone surface. For all simulations, convergence to the steady state of the flow field was achieved through reduction of the normalized residuals by four to five orders of magnitude. 


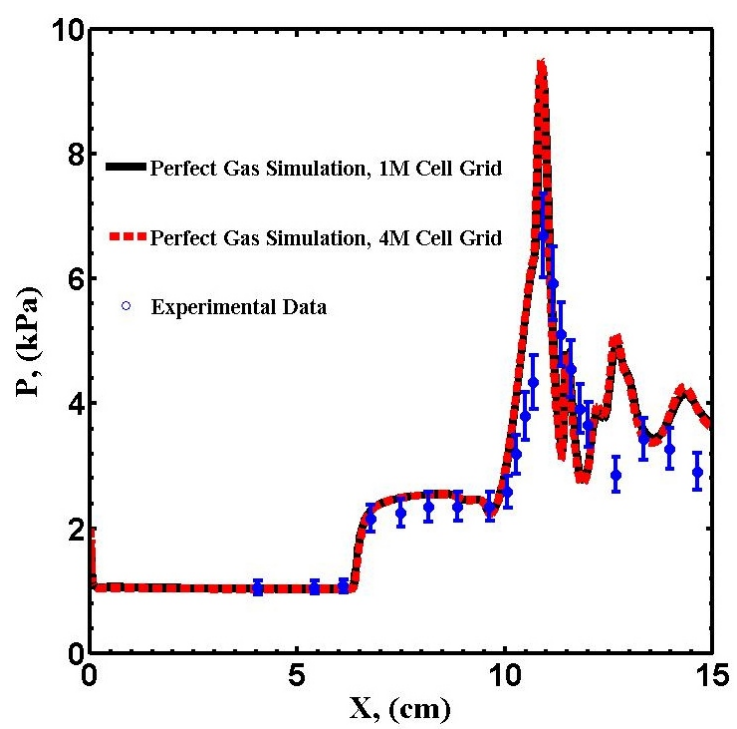

(a)

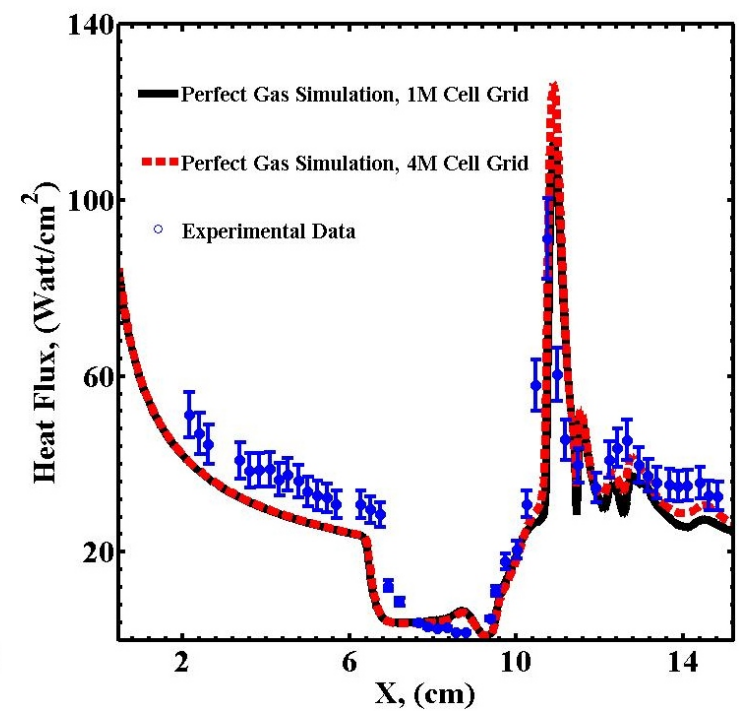

(b)

Figure 5. Computed results for Run 1, Table 1, for different grid refinement levels. (a) Surface pressure; (b) Heat transfer rate.

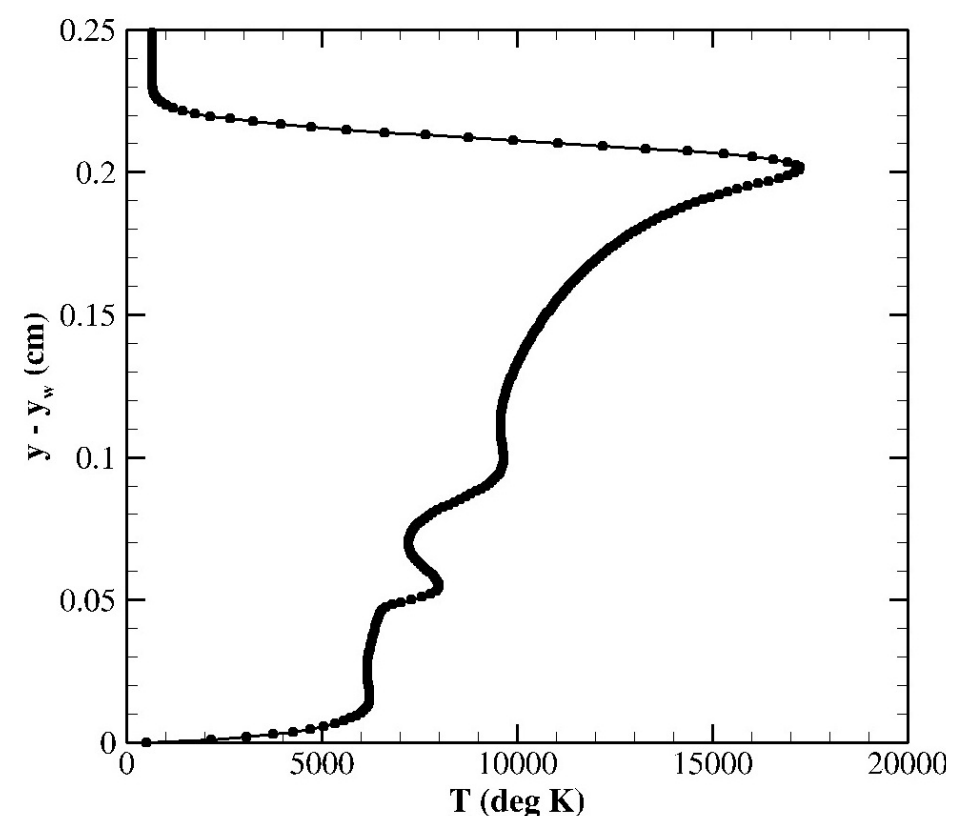

Figure 6. Static temperature for Run 4 (non-equilibrium Navier-Stokes) at $x=9.756 \mathrm{~cm}$.

The computed and experimental surface pressure and heat transfer for Run 2 (Table 1) are presented in Figure 7. The non-equilibrium Navier-Stokes simulation accurately predicts the location of separation, peak pressure and reattachment point at $x \approx 7.6 \mathrm{~cm}, x \approx 10.1 \mathrm{~cm}$ and $x \approx 10.7 \mathrm{~cm}$, respectively. The flow field structure for Run 2 is shown in Figure 8 and is similar to Run 1.

Among all of the published double-cone simulations so far, there were only three simulations of a $25^{\circ}$ and $55^{\circ}$ double-cone in air [11,34,35]. The freestream Mach number in [11,34] is 8.87, which does not match any of the four Runs presented here. Freestream conditions in [35] are similar to Run 2. Comparison of the computed surface pressure and heat transfer for these two similar cases indicates that the predicted peak heat transfer in [35] is $15 \%$ below the experimental data, while the Run 2 
nonequilibrium computations are within experimental uncertainty (i.e., $\pm 10 \%$ ). Both simulations underpredict the size of the separation bubble, however.

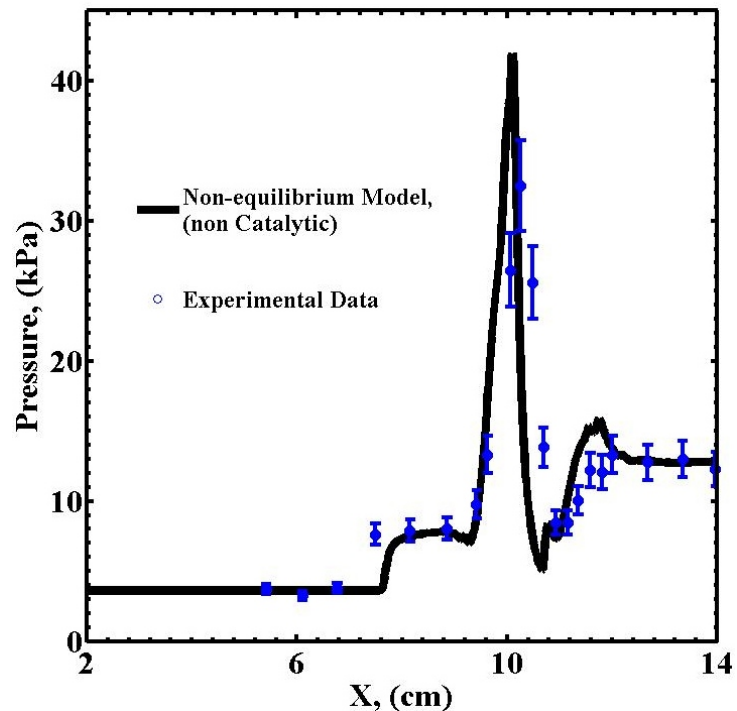

(a)

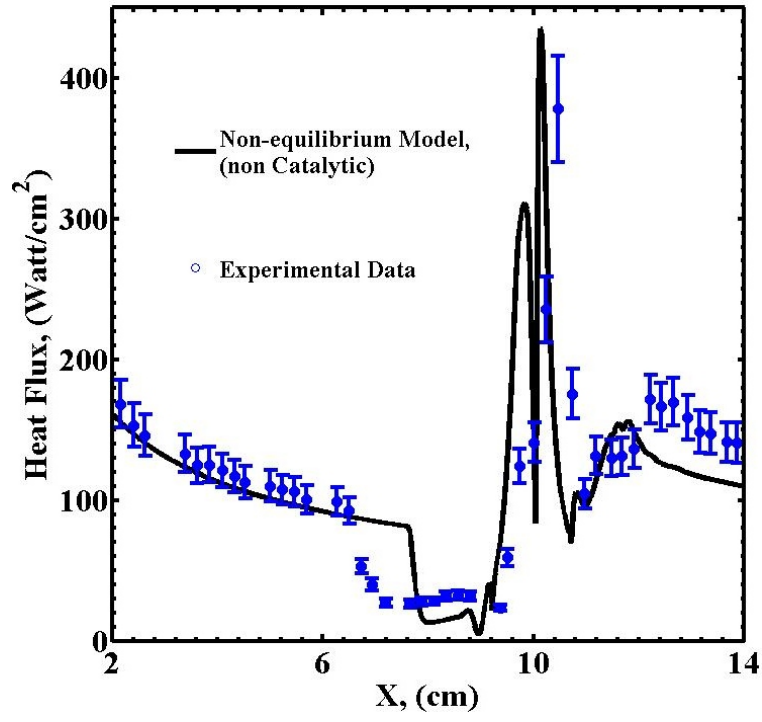

(b)

Figure 7. Computational results for Run 2, Table 1, using the non-equilibrium Navier-Stokes model. (a) Surface pressure; (b) Heat transfer rate.

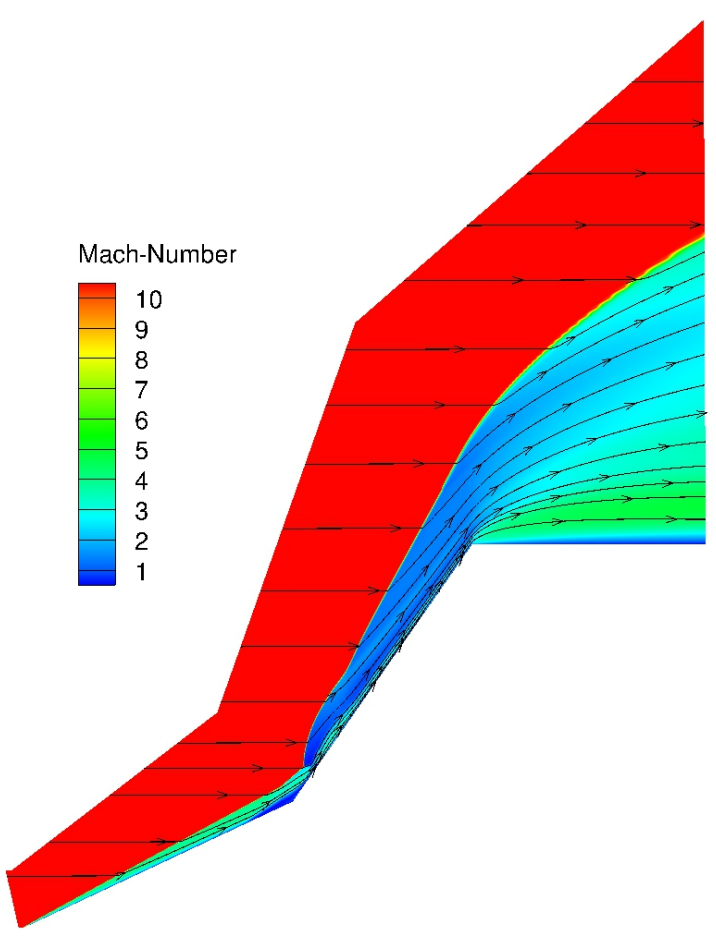

(a)

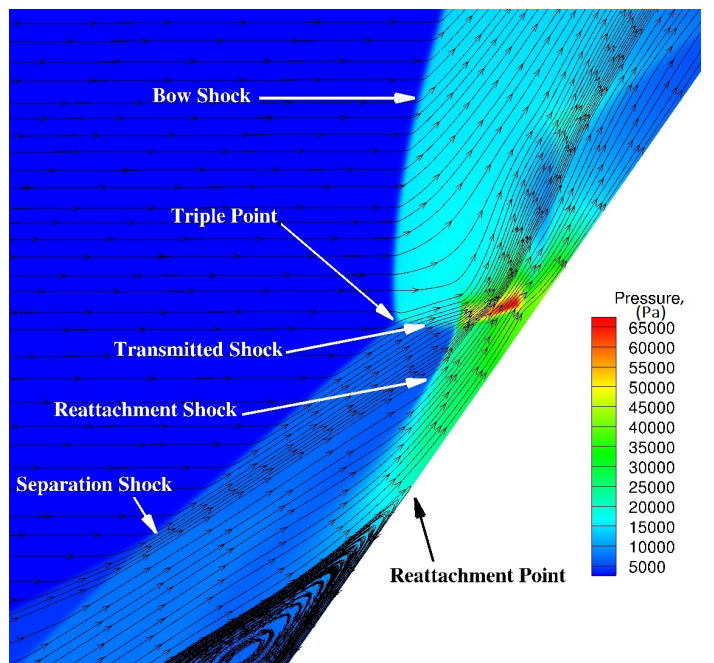

(b)

Figure 8. Flow field structure for Run 2, Table 1, using the non-equilibrium Navier-Stokes model. (a) Overall flow field; (b) Enlargement of flow field.

The computed and experimental surface pressure and heat transfer for Run 6 (Table 1) are presented in Figure 9. The nonequilibrium model underpredicts the size of the separation region 
by $1.1 \mathrm{~cm}$, but it displays general agreement with the overall pressure and heat transfer plateau. Comparison between Figure $10 \mathrm{~b}$ with the previous runs shows that the jet generated from the triple point is now impinging on the wall and generates the second pressure spike seen in Figure 9a.

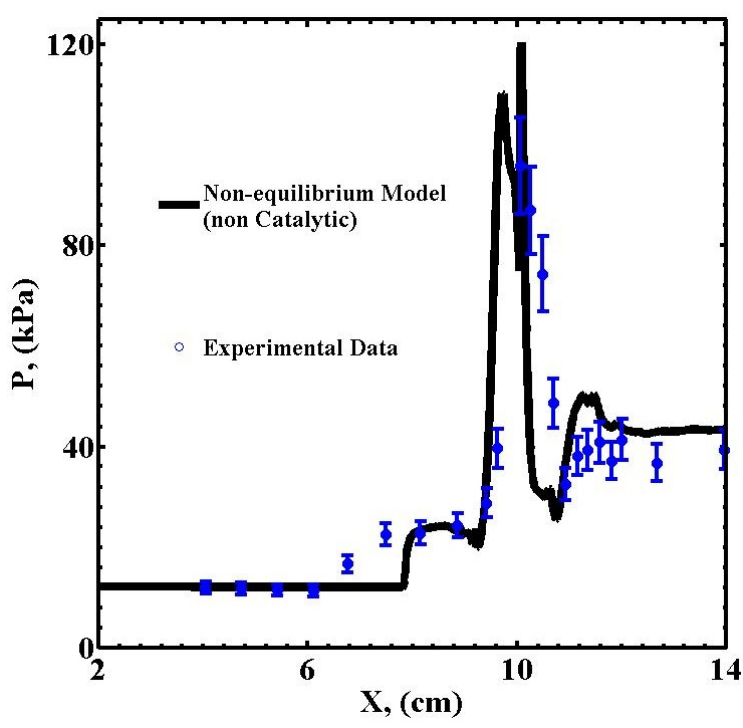

(a)

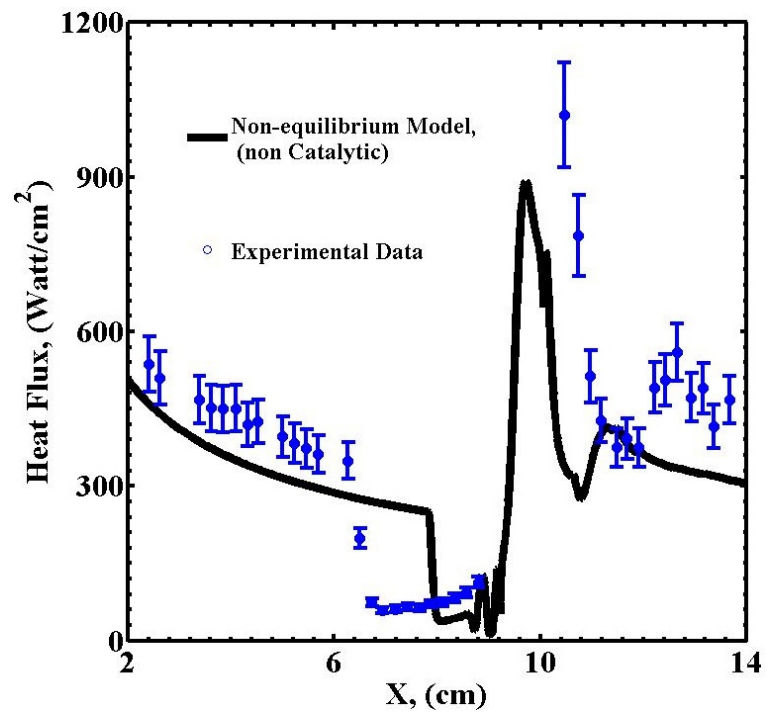

(b)

Figure 9. Computational results for Run 6, Table 1, using the non-equilibrium Navier-Stokes model. (a) Surface pressure; (b) Heat transfer rate.

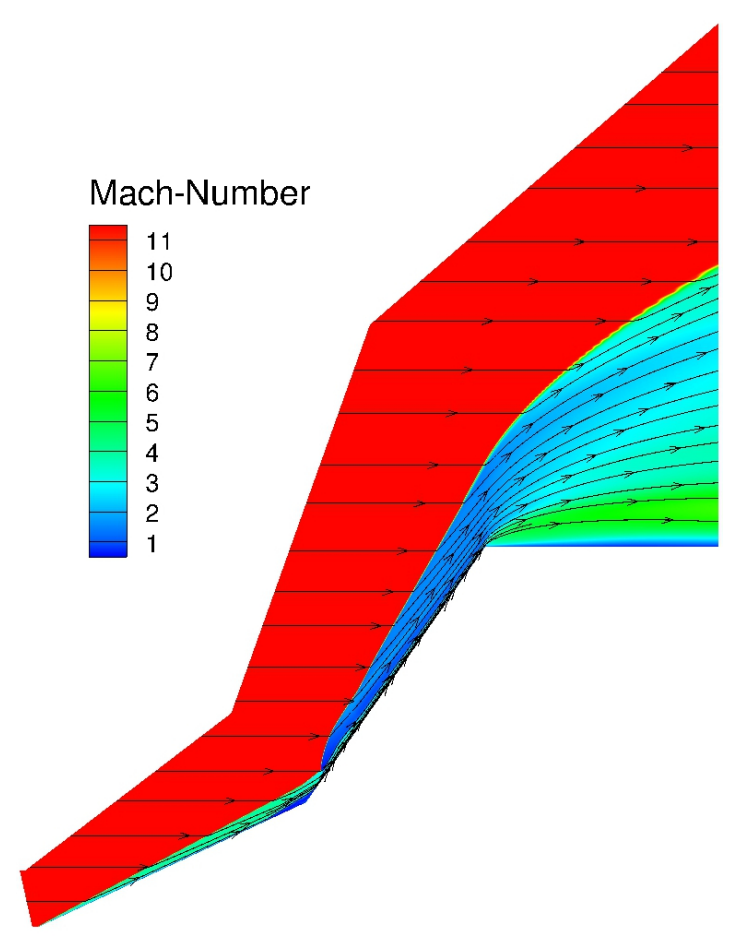

(a)

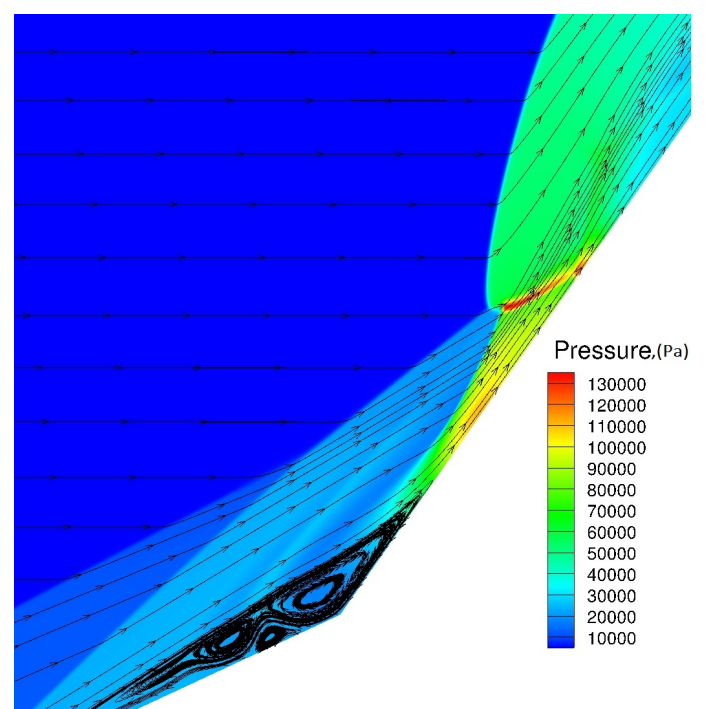

(b)

Figure 10. Flow field structure for Run 6, Table 1, using the non-equilibrium Navier-Stokes model. (a) Overall flow field; (b) Enlargement of flow field. 
The computed and experimental surface pressure and heat transfer for Run 4 are presented in Figure 11. The non-equilibrium Navier-Stokes simulations were performed for both non-catalytic and air catalysis boundary conditions at the wall and have less than a 10\% difference with the experimental data, although the former predicts slightly more accurate results for the recovery of the heat transfer downstream of reattachment. The predicted size of the separation region, the location of peak pressure and recovery of the pressure downstream of reattachment have less than a $0.1-\mathrm{cm}$ difference with the experimental data. The computed surface heat transfer is within $10 \%$ of the experiment with the exception of the consistent underprediction on the forward cone upstream of the shock wave boundary layer interaction and downstream of the second cone. It is noted that several independent computations for the same double-cone cases presented at the AIAA AVIATION 2014 conference showed similar underprediction of the surface heat transfer on the forward cone using different codes $[19,20]$. One possible explanation for this discrepancy could be the heating of the wall in the experiment, since the computations performed for this set of experimental data assumed a constant wall temperature. A closer look in the flowfield structure in Figure 12 reveals that just one triple point is distinguishable in contrast to Run 1 in Figure 4. Here again the impingement of the supersonic jet bounded by two slip lines on the surface of the doublecone results in the formation of a region of large pressure and heat transfer.

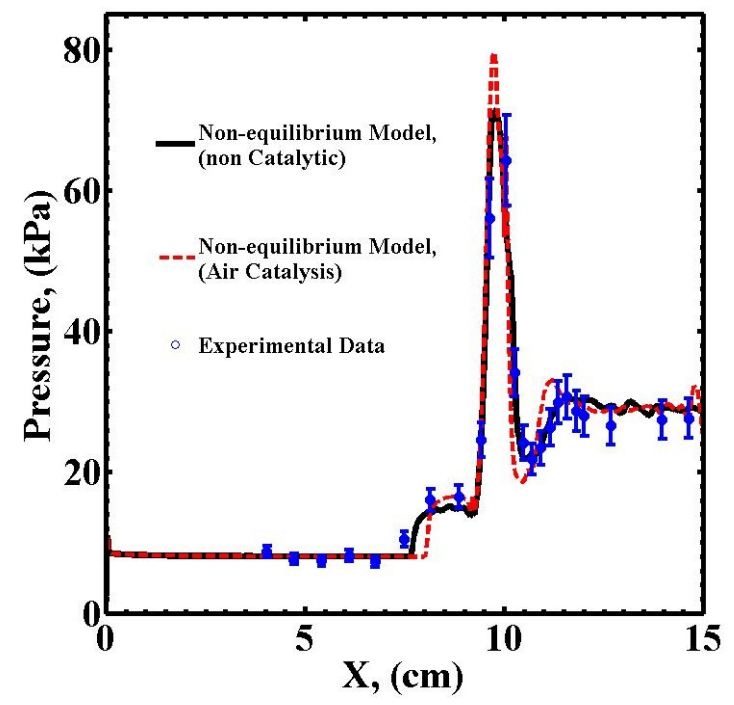

(a)

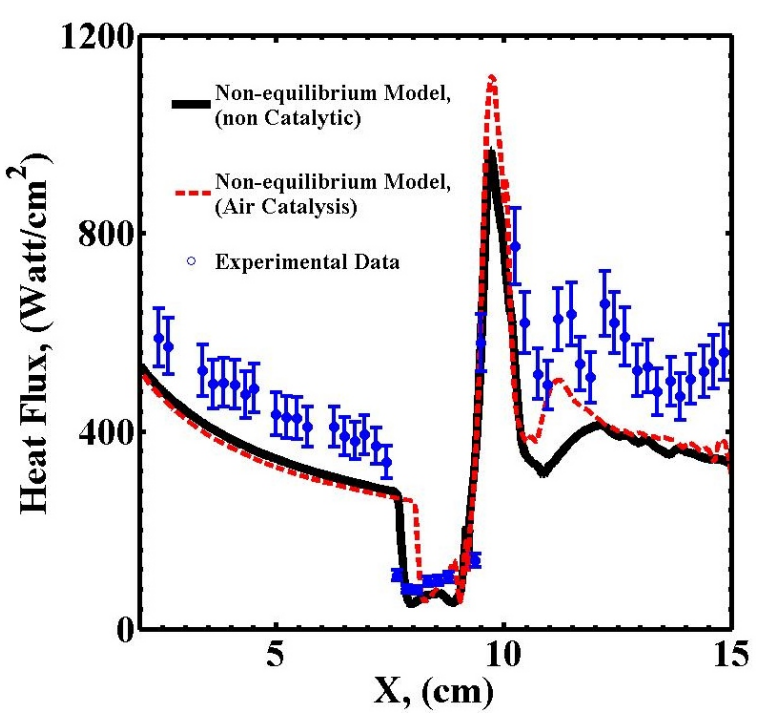

(b)

Figure 11. Computational results for Run 4, Table 1, using the non-equilibrium Navier-Stokes model. (a) Surface pressure; (b) Heat transfer rate.

The species mass fractions are scaled based on the maximum mass fraction of $N, O$ and $N O$ for all runs and are illustrated in Figure 13. The maximum mass fractions of these species for all runs are tabulated in Table 4 . The last column, which corresponds to Run 4, has the maximum dissociation and was used for scaling. For the higher stagnation enthalpy runs, a significant rate of dissociation can be observed in Figure 13. The bow shock is sufficiently strong to dissociate significant amounts of $N_{2}$ and $\mathrm{O}_{2}$ and produce monatomic species, as can be observed from Figure 13a-c and 13d-f. These species can recombine to produce noticeable mass fractions of $N O$, as can be seen in Figure 13g-i. 
Table 4. Maximum of species mass fractions.

\begin{tabular}{ccccc}
\hline Run Number & Run 1 & Run 2 & Run 6 & Run 4 \\
\hline Mass Fraction of $N$ & $3.53 \times 10^{-5}$ & 0.0064 & 0.0844 & 0.1840 \\
Mass Fraction of $O$ & 0.0136 & 0.1569 & 0.2346 & 0.2349 \\
Mass Fraction of NO & 0.0021 & 0.0836 & 0.0886 & 0.0926 \\
\hline
\end{tabular}

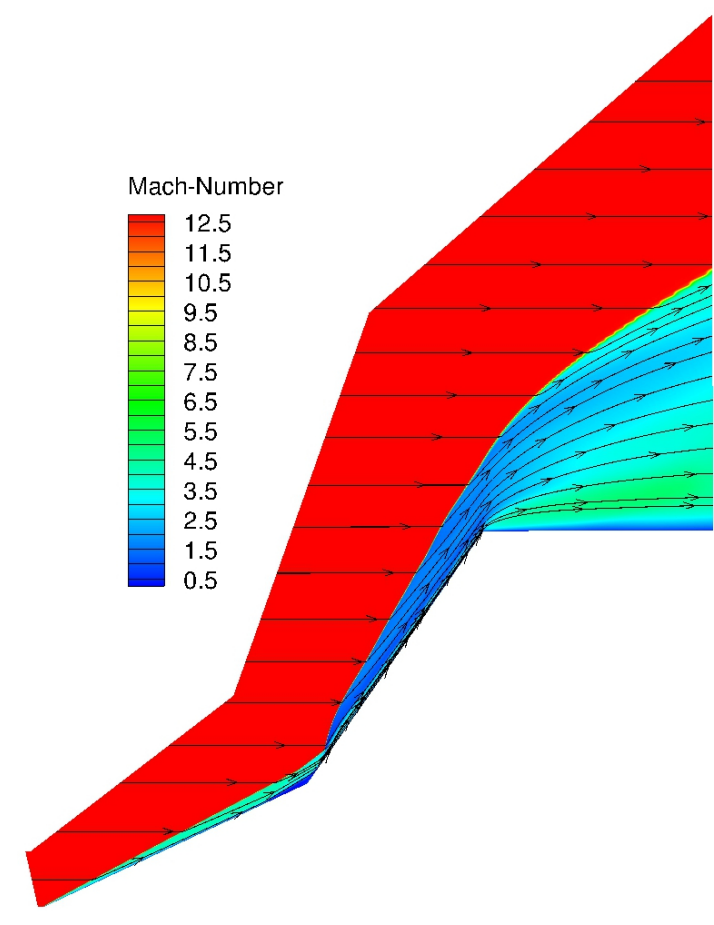

(a)

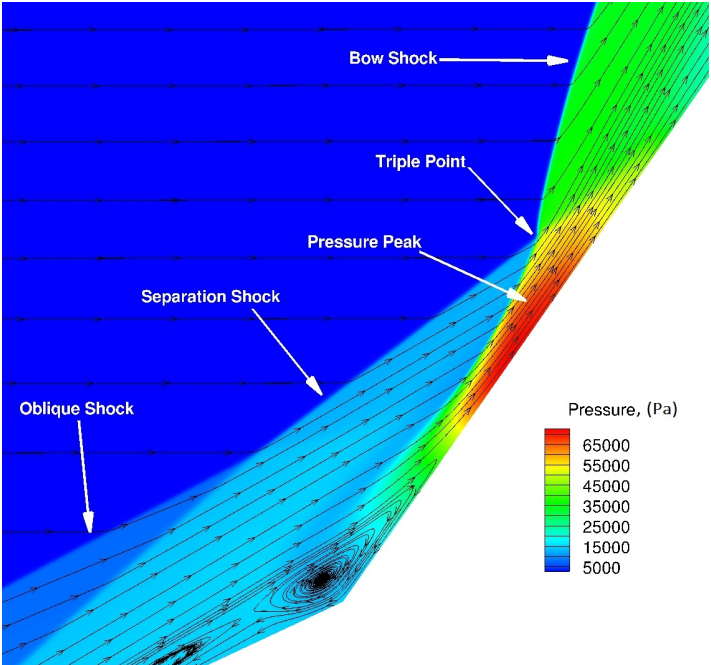

(b)

Figure 12. Flow field structure for Run 4, Table 1, using the non-equilibrium Navier-Stokes model (non-catalytic). (a) Overall flow field; (b) Enlargement of flow field.

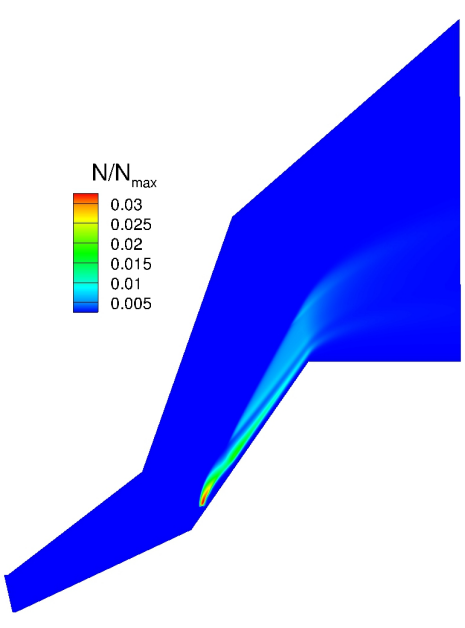

(a)

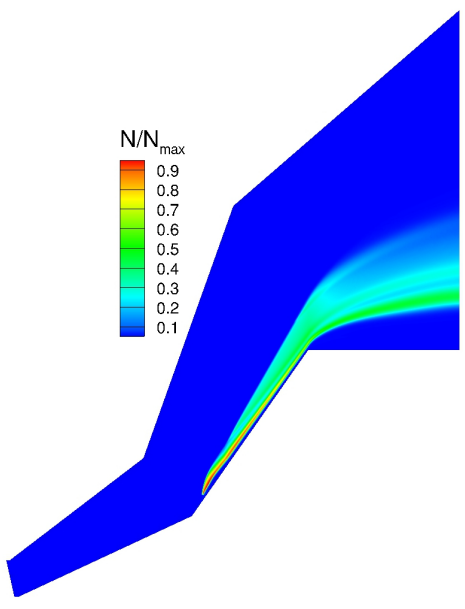

(b)

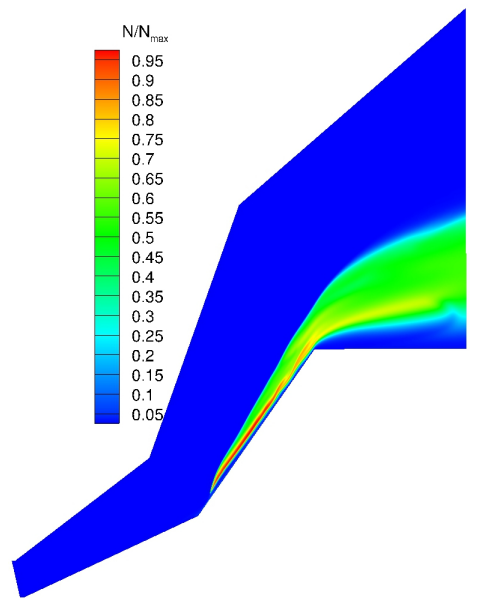

(c)

Figure 13. Cont. 


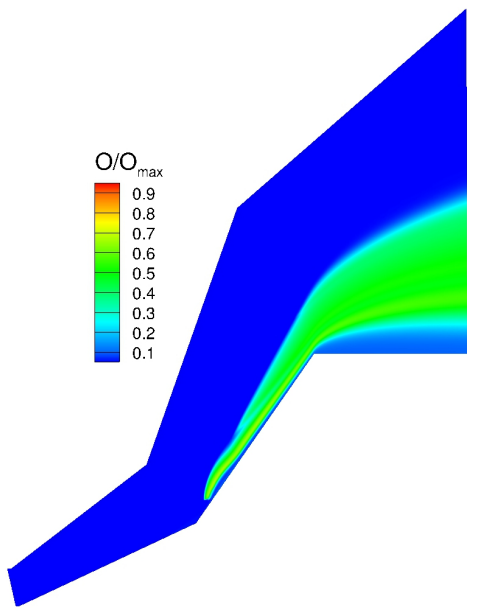

(d)

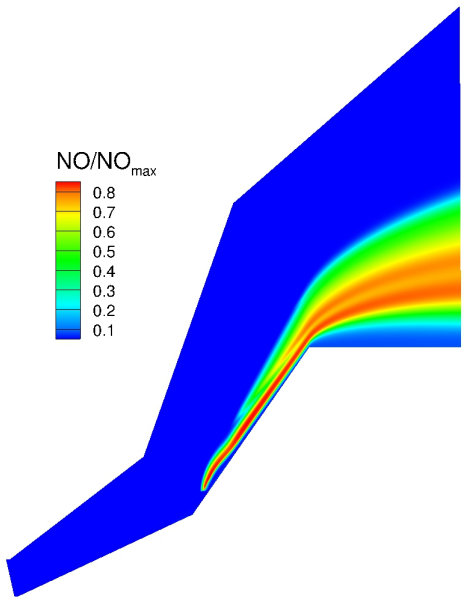

(g)

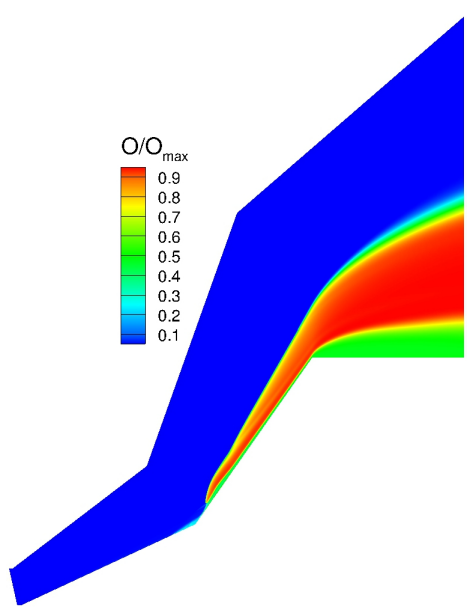

(e)

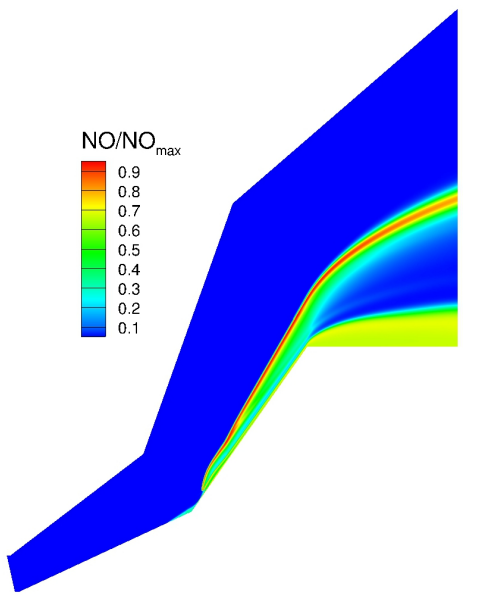

(h)

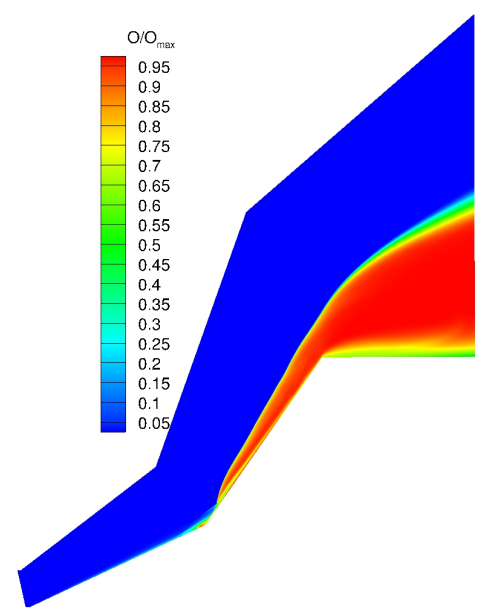

(f)

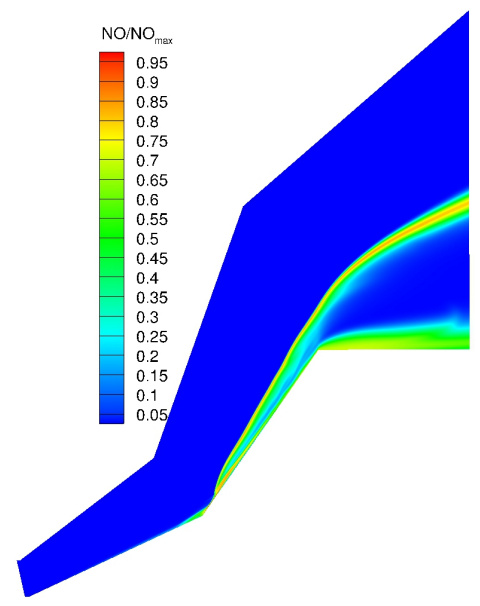

(i)

Figure 13. Species mass fractions, Table 1, (non-equilibrium Navier-Stokes model, non-catalytic). (a) Mass fraction of $\mathrm{N}$ for Run 2; (b) Mass fraction of $\mathrm{N}$ for Run 6; (c) Mass fraction of $\mathrm{N}$ for Run 4;

(d) Mass fraction of $\mathrm{O}$ for Run 2; (e) Mass fraction of $\mathrm{O}$ for Run 6; (f) Mass fraction of $\mathrm{O}$ for Run 4;

(g) Mass fraction of NO for Run 2; (h) Mass fraction of NO for Run 6; (i) Mass fraction of NO for Run 4.

The difference between vibrational temperature and translational-rotational temperature is shown in Figure 14. The averaged vibrational temperature $T_{\mathrm{avg}}^{\mathrm{vib}}$ is determined assuming an equilibrium vibrational distribution at the averaged vibrational energy $e_{\text {avg }}^{\text {vib }}$ defined as:

$$
e_{\mathrm{avg}}^{\mathrm{vib}}=\sum_{\alpha=1}^{m} Y_{\alpha} e_{\alpha}^{\mathrm{vib}}
$$

The vibrational temperature is significantly below the translational-rotational temperature downstream of the shock waves generated by the forward and rear cones, as can be seen in Figure 14a-c. This difference is attributable to the vibrational relaxation time [24]. The vibrational temperature relaxes more rapidly downstream of the rear shock due to the higher density compared to immediately downstream of the forward shock. Downstream of the corner the sudden drop in static temperature due to expansion generates the opposite result due to vibrational "freezing" in the expansion. The maximum difference between translational-rotational and vibrational temperatures downstream of the forward and rear shocks varies from $4000 \mathrm{~K}$ for Run 2 to $8000 \mathrm{~K}$ for Run 4. 


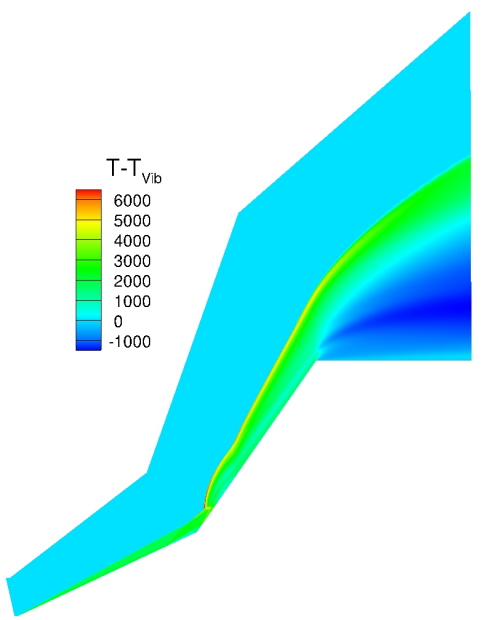

(a)

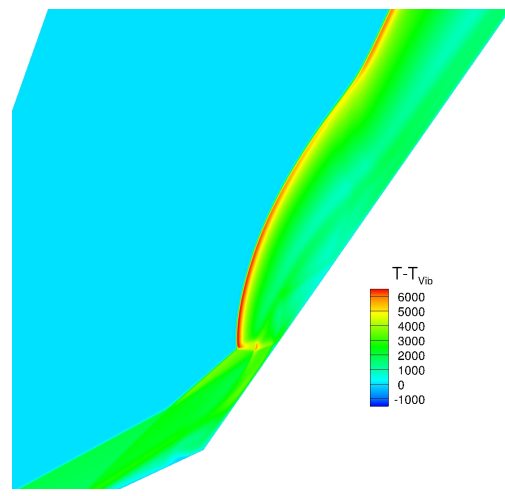

(d)

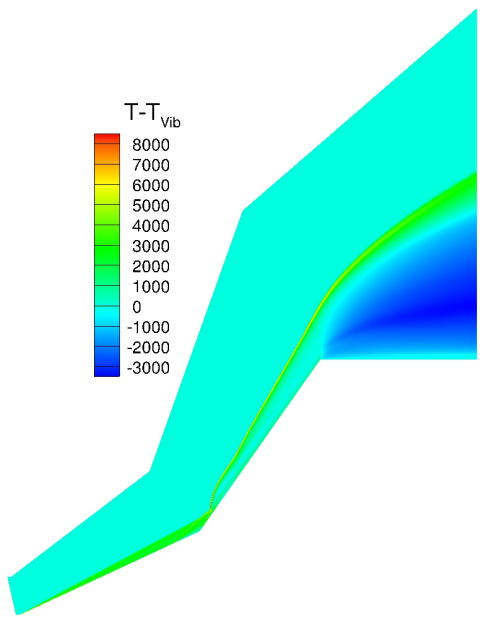

(b)

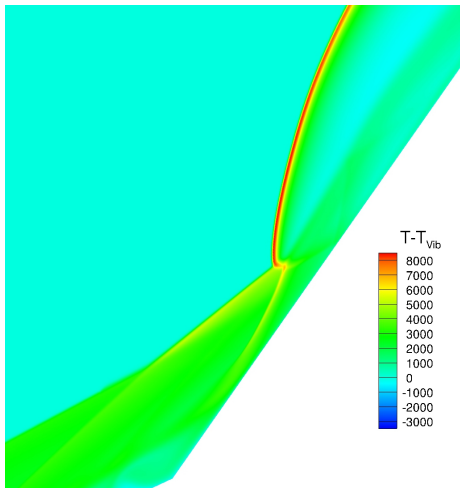

(e)

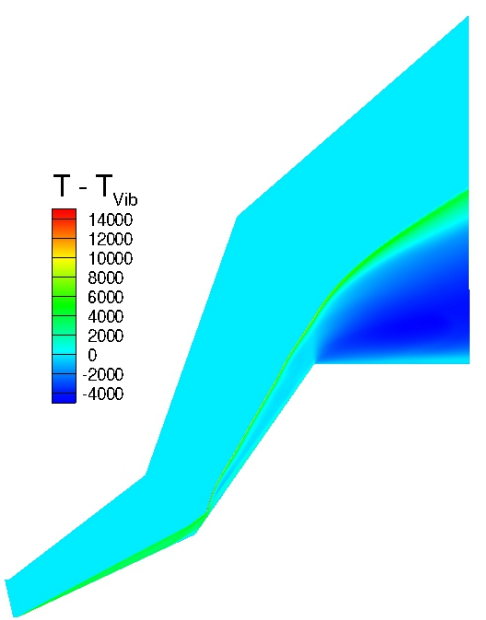

(c)

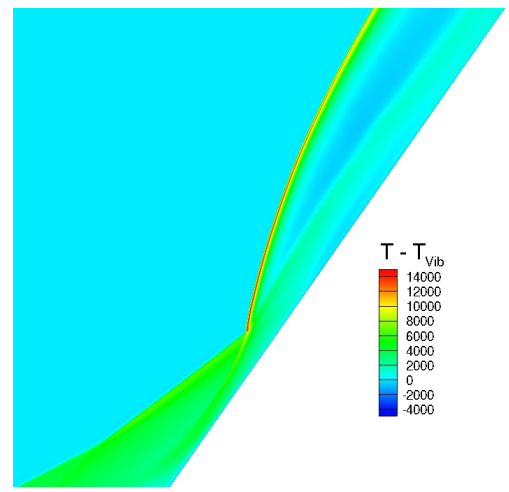

(f)

Figure 14. $T-T_{V i b}$. (a) $T-T_{V i b}$ Run 2; (b) $T-T_{V i b}$ Run 6; (c) $T-T_{V i b}$ Run 4; (d) $T-T_{V i b}$ Run 2 enlargement; (e) $T-T_{V i b}$ Run 6 enlargement; (f) $T-T_{V i b}$ Run 4 enlargement.

By comparison of the governing equations for the perfect gas and nonequilibrium models, the difference is the additional physical models, namely (1) thermochemical effects including dissociation of species (2) vibrational excitation and (3) thermodynamic and transport properties of species. The differences between the predictions of the perfect gas model and nonequilibrium model simulations is due to one or more of the aforementioned features. However, experimental data are only available for surface pressure and heat transfer. Flow field measurements including species concentration measurements are required to distinguish the role of these nonequilibrium features and can be the topic of future research.

\section{Conclusions}

The objective of this study is the assessment of CFD capability for prediction of hypersonic shock wave laminar boundary layer interaction for the double-cone configuration at stagnation enthalpies from $5.44 \mathrm{MJ} / \mathrm{kg}$ to $21.77 \mathrm{MJ} / \mathrm{kg}$ and Mach numbers from 10.9 to 12.82. Simulations are performed for four separate cases. Results are presented for simulations using both perfect gas Navier-Stokes equations $(5.44 \mathrm{MJ} / \mathrm{kg}$ ) and non-equilibrium Navier-Stokes equations using the Park I thermochemistry model and Landau-Teller translational-vibrational energy exchange model (5.44 MJ $/ \mathrm{kg}$ to $21.77 \mathrm{MJ} / \mathrm{kg}$ ). The perfect gas Navier-Stokes simulations accurately predict the experimental surface pressure and heat transfer for the $5.44 \mathrm{MJ} / \mathrm{kg}$ case. The non-equilibrium Navier-Stokes simulations underpredict the separation region size for all cases except $21.77 \mathrm{MJ} / \mathrm{kg}$. 
The non-equilibrium Navier-Stokes simulations accurately predict the plateau pressure in the separation region and the location of peak pressure and heat transfer at reattachment. The computed peak pressure and heat transfer exceed the peak measured values for all cases; however, in view of the finite spacing between experimental gauges and the high gradients in surface pressure and heat transfer at reattachment, the higher computed values may not necessarily be in error. Further research is needed to ascertain the defects in the non-equilibrium Navier-Stokes model.

Acknowledgments: The research was supported by the Emil Buehler Foundation, the U.S. Office of Naval Research under Grant ONR-N00014-14-1-0827 (Gil Graff, Program Manager) and Rutgers University. The views and conclusions contained herein are those of the authors and should not be interpreted as necessarily representing the official policies or endorsements, either expressed or implied, of the Office of Naval Research, nor the U.S. Government.

Author Contributions: Mehrnaz Rouhi Youseffi performed the perfect gas simulations, analyzed the perfect gas and non-equilibrium simulations and wrote the paper. Doyle Knight performed the non-equilibrium simulations.

Conflicts of Interest: The authors declare no conflict of interest. The founding sponsors had no role in the design of the study; in the collection, analyses or interpretation of data; in the writing of the manuscript; nor in the decision to publish the results.

\section{References}

1. Babinsky, H.; Harvey, J. Shock Wave-Boundary-Layer Interactions; Cambridge: New York, NY, USA, 2011.

2. Olejniczak, J.; Candler, G.; Hornung, H. Computation of Double-Cone Experiments in High Enthalpy Nitrogen; AIAA Paper 1997-2549; American Institute of Aeronautics and Astronautics: Reston, VA, USA, 1997.

3. Wright, M.; Sinha, K.; Olejniczak, J.; Candler, G.; Magruder, T.; Smits, A. Numerical and Experimental Investigation of Double-Cone Shock Interactions. AIAA J. 2000, 38, 2268-2276.

4. Gnoffo, P. CFD Validation Studies for Hypersonic Flow Prediction; AIAA Paper 2001-1025; American Institute of Aeronautics and Astronautics: Reston, VA, USA, 2001.

5. Kato, H.; Tannehill, J. Computation of Hypersonic Laminar Separated Flows Using an Iterated PNS Algorithm; AIAA Paper 2001-1028; American Institute of Aeronautics and Astronautics: Reston, VA, USA, 2001.

6. Roy, C.; Gallis, M.; Bartel, T.; Payne, J. Navier-Stokes and Direct Simulation Monte-Carlo Predictions for Laminar Hypersonic Separation. AIAA J. 2003, 41, 1055-1063.

7. Reimann, B.; Hannemann, V. Numerical Investigation of Double Cone and Cylinder Experiments in High Enthalpy Flows Using DLR TAU Code; AIAA Paper 2010-1282; American Institute of Aeronautics and Astronautics: Reston, VA, USA, 2010.

8. Youseffi, M.R.; Knight, D. Assessment of CFD Capability for Hypersonic Shock Wave Boundary Layer Interactions, Part II; AIAA Paper 2016-0350; American Institute of Aeronautics and Astronautics: Reston, VA, USA, 2016.

9. Youseffi, M.R.; Knight, D. Assessment of CFD Capability for High Enthalpy Non-Equilibrium Flows with Strong Viscous-Inviscid Interaction; AIAA Paper 2015-0580; American Institute of Aeronautics and Astronautics: Reston, VA, USA, 2015.

10. Chanetz, B. Low and High Enthalpy Shock-Wave/Boundary Layer Interactions around Cylinder-Flare Models. In EUCASS Progress in Flight Physics Volume 3; Reijasse, P., Knight, D., Ivanov, M., Lipatov, I., Eds.; EDP Sciences and Torus Press: Moscow, Russia, 2012; pp. 107-118.

11. Tissera, S.; Titarev, V.; Drikakis, D. Chemically Reacting Flows around a Double Cone, Including Ablation Effects; AIAA Paper 2010-1285; American Institute of Aeronautics and Astronautics: Reston, VA, USA, 2010.

12. Coblish, J.; Smith, M.; Hand, T.; Candler, G.; Nompelis, I. Double-Cone Experiment and Numerical Analysis at AEDC Hypervelocity Wind Tunnel No. 9; AIAA Paper 2005-0902; American Institute of Aeronautics and Astronautics: Reston, VA, USA, 2005.

13. Holden, M.; Wadhams, T. Code Validation Study of Laminar Shock/Boundary Layer and Shock/Shock Interactions in Hypersonic Flow. Part A: Experimental Measurements; AIAA Paper 2001-1031 (Part A); American Institute of Aeronautics and Astronautics: Reston, VA, USA, 2001.

14. Harvey, J.; Holden, M.; Wadhams, T. Code Validation Study of Laminar Shock/Boundary Layer and Shock/Shock Interactions in Hypersonic Flow. Part B: Comparison with Navier-Stokes and DSMC Solutions; AIAA Paper 2001-1031 (Part B); American Institute of Aeronautics and Astronautics: Reston, VA, USA, 2001. 
15. Candler, G.; Nompelis, I.; Druguet, M.C.; Holden, M.; Wadhams, T.; Boyd, I.; Wang, W.L. CFD Validation for Hypersonic Flight: Hypersonic Double-Cone Flow Simulations; AIAA Paper 2002-0581; American Institute of Aeronautics and Astronautics: Reston, VA, USA, 2002.

16. Nompelis, I.; Candler, G.; Holden, M. Effect of Vibrational Nonequilibrium on Hypersonic Double-Cone Experiments. AIAA J. 2003, 41, 2162-2169.

17. Nompelis, I.; Candler, G.; MacLean, M.; Wadhams, T.; Holden, M. Numerical Investigation of High Enthalpy Chemistry on Hypersonic Double-Cone Experiments; AIAA Paper 2005-0584; American Institute of Aeronautics and Astronautics: Reston, VA, USA, 2005.

18. CUBRC. Shock Wave/Laminar Boundary Layer Interaction with Real-gas Effects Presented at AIAA Aviation 2014. Available online: http:/ /www.cubrc.org/index.php/page/publications (accessed on 23 April 2017).

19. MacLean, M.; Holden, M.; Dufrene, A. Comparison between CFD and Measurements for Real-Gas Effects on Laminar Shock Wave Boundary Layer Interaction, I; Oral Presentation; AIAA Aviation 2014: Atlanta, GA, USA, 2014.

20. MacLean, M.; Holden, M.; Dufrene, A. Comparison between CFD and Measurements for Real-Gas Effects on Laminar Shock Wave Boundary Layer Interaction, II; Oral Presentation; AIAA Aviation 2014: Atlanta, GA, USA, 2014.

21. Landau, L.; Teller, E. Zur Theorie der Schalldispersion. Physikalische Zeitschrift der Sowjetunion 1936, 10, 34-43. (In German)

22. Park, C. On Convergence of Computation of Chemically Reacting Flow; AIAA Paper 1985-0247; American Institute of Aeronautics and Astronautics: Reston, VA, USA, 1985.

23. MacLean, M. (Buffalo, NY, USA). Private communication, 29 July 2016.

24. Vincenti, W.; Kruger, C. Introduction to Physical Gas Dynamics; Krieger Publishing Company: Malabar, FL, USA, 1965.

25. Millikan, R.; White, D. Systematics of Vibrational Relaxation. J. Chem. Phys. 1963, 39, 3209-3213.

26. GASP Version 5.1.2 Reference Guide; Aerosoft, Inc.: Blacksburg, VA, USA, 2014.

27. Leer, B.V. Flux Vector Splitting for the Euler Equations. In Eighth International Conference on Numerical Methods in Fluid Dynamics; Springer: Berlin, Germany, 1982; pp. 507-512.

28. Knight, D.; Yan, H.; Panaras, A.; Zheltovodov, A. RTO WG 10: CFD Validation for Shock Wave Turbulent Boundary Layer Interactions; RTO Technical Report TR-AVT-007-V3; NATO: Paliseau, France, 2006.

29. Withington, J.; Yang, V.; Shuen, J. A Time-Accurate Implicit Method for Chemically Reacting Flows at All Mach Numbers; AIAA Paper 1991-0581; American Institute of Aeronautics and Astronautics: Reston, VA, USA, 1991.

30. Park, S.H.; Kwon, J.H. On the Dissipation Mechanism of Godunov-type Schemes. J. Comput. Phys. 2003, 188, 524-542.

31. Roe, P. Approximate Reimann Solvers, Parameter Vectors, and Difference Schemes. J. Comput. Phys. 1981, 43, 357-372.

32. Druguet, M.C.; Candler, G.; Nompelis, I. Effects of Numerics on Navier-Stokes Computations of Hypersonic Double-Cone Flows. AIAA J. 2005, 43, 616-623.

33. Gaitonde, D. An Assessment of CFD for Prediction of 2-D and 3-D High-Speed Flows; AIAA Paper 2010-1284; American Institute of Aeronautics and Astronautics: Reston, VA, USA, 2010.

34. Druguet, M.C.; Candler, G.; Nompelis, I. Comparison of Physical Models in Computations of High-Enthalpy Double-Cone Flows; AIAA Paper 2006-3419; American Institute of Aeronautics and Astronautics: Reston, VA, USA, 2006.

35. Nompelis, I.; Candler, G.; Holden, M.; Wadhams, T. Computational Investigation of Hypersonic Viscous/Inviscid Interactions in High Enthalpy Flows; AIAA Paper 2003-3642; American Institute of Aeronautics and Astronautics: Reston, VA, USA, 2003.

(C) 2017 by the authors. Licensee MDPI, Basel, Switzerland. This article is an open access article distributed under the terms and conditions of the Creative Commons Attribution (CC BY) license (http:/ / creativecommons.org/licenses/by/4.0/). 